\title{
INFLUENCE OF A TRAILING EDGE FLAP ON A VERTICAL AXIS WIND TURBINE PERFORMANCE
}

\author{
G. A. Z. Mousa, A. Abd Elmotalip, Gamal H. Moustafa \\ Faculty of Engineering, Suez Canal University
}

\begin{abstract}
The present research was carried out to summarize the effect of an attached flap at the trailing edge on a vertical axis wind turbine performance. Two models were tested in a wide range of initial flow velocity and blade pitch angles. The first model has two blades, and in the second model four blades were used. The pitch angle was varied from $15^{\circ}$ to $60^{\circ}$. The torque and power coefficients were measured. A comparison with data obtained with the model without flaps is given. It is found that the torque and power coefficients increase with increasing the pitch angle up to $45^{\circ}$ and then decrease at the a higher value of the pitch angle. The attached flap reduces the flow separation, enhances lift, captures more wind energy, increases the rotor speed and hence increases the torque and power coefficients. The flap at a position $\mathrm{L} / \mathrm{C}_{\mathrm{f}}=0.75$ for the rotor has a pitch angle of $45^{\circ}$ gives an optimum value of the power and torque coefficients compared to the other values of $L / C_{f}$ . At these conditions, an improvement of $7.14 \%$ is achieved (for the rotor has two blades), and of $12.7 \%$ (for the rotor has four blades) compared to the rotor without flaps.

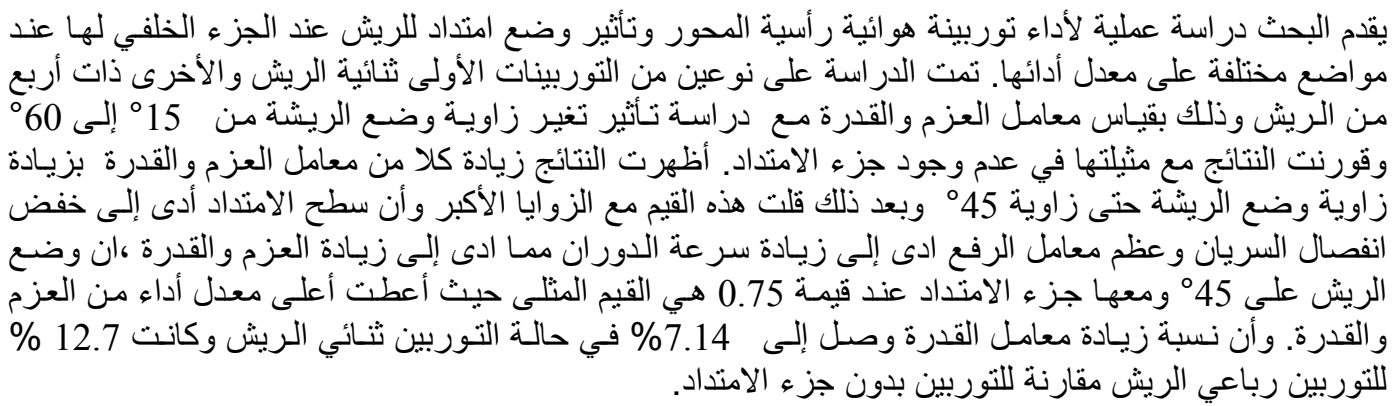

Keywords: Wind Energy, Wind Turbines, and Power Augmentation.

\section{INTRODUCTION}

The power of wind has been used for a long time to generate electricity. Today, wind turbines play an increasingly important role in meeting the electricity needs. They currently produce over three billion kilowatt-hours of electricity annually which is enough to meet the needs of over one million people Iqbal (2003). The production of energy is one of the most far-reaching of human activities in terms of its environmental impacts. Wind energy and other renewable energy sources, such as solar and geothermal energy; offer the prospect of producing large amounts of electricity with greatly reduced effects on the environment.

The vertical axis wind turbines are used widely in small-scale applications of wind energy conversion systems. This is due to the smaller support structure, low cost, less noise, wind direction independency, and good starting torque performance (Fujisawa and Gotoh, 1994). However, the aerodynamic performance is less efficient compared with the other types of wind turbine such as propeller types. Hence, further study of the vertical axis wind turbines is needed.

In fact, the utilization of wind energy may be an attractive alternative in places where fuel is unusually expensive and wind regimes are particularly favorable. These conditions are likely to occur in places which are geographically removed and have week, autonomous power systems. Gavanidou et al. (1992) studied a probabilistic method for predicting the performance of autonomous wind-diesel energy systems based on statistical data of the system load and the wind speed and obtained the optimum wind penetration to an already existing diesel system. Wind turbine operating experience has shown that current analysis techniques are inadequate when used to predict peak power and loads on a fixed pitch wind turbine. Pitch controlled wind turbines regulate their peak power by reducing pitch angle, which reduces the average aerodynamic loading (Butterfield et al., 1992).

Many wind turbine sites have restrictions on rotor diameter in one form or another. In those cases, the only way the power production which can be 
optimized at any specific wind velocity is through maximizing the power coefficient of the wind turbine. To that end, flaps can be used, since these can improve the power production without increasing the projected rotor area. The viscous flow and dynamic stall effects on vertical axis wind turbines were studied by Allet and Paraschivoiu(1995). Numerical predictions of wind turbine power and aerodynamic loads for the horizontal axis wind turbine were studied by Duque, et. al. (2000). A numerical method for performance predictions of wind turbines immersed into stable, neutral or unstable atmospheric boundary layer was described by Alinot and Masson, (2002). Abd Elmotalip (2005) studied the effect of an extended curved vane on the power coefficient of four-bladed vertical axis wind turbine. An improvement in the maximum power coefficient by about $9.2 \%$ which occurs at a blade pitch angle $=45^{\circ}$ is found. Gaunaa, and Johansen (2007) showed that winglets could be used successfully to increase the power coefficient. The positive effect of winglets on the power production is due to a reduction of tip losses. A straight bladed vertical axis wind turbine (S-VAWT) with a directed guide vane row was studied by Takao, et al. (2008). The power coefficient was approximately 1.5 times higher than that of the S-VAWT without guide vanes.

It is known that the mechanical power output of a simple rotor depends on the wind speed and the effective area of the rotor. The power coefficient for simple wind rotors has a theoretical upper limit at 0.593 , that is known as the Betz limit. Some designs of wind rotors have peak power coefficients close to 0.5 . However, the peak power coefficient of common wind rotors is in the range of 0.2 to 0.4 , Katz and Plotkin (2006). The present study aims to describe the effect of an attached flap to the trailing edge on the torque and power coefficients. The effect of the blade pitch angle as well as the initial wind speed on the captured energy is considered.

\section{EXPERIMENTAL TEST RIG AND PROCEDURE}

Experiments were done on the vertical axis wind turbine, Fig.(1). An open jet type wind tunnel has $300 \mathrm{~mm} \times 300 \mathrm{~mm}$ cross sectional area was used to rotate the wind turbine. Two centrifugal air blowers were used to provide the required air flow rate. The available maximum flow rate was $50 \mathrm{~m}^{3} / \mathrm{min}$. An AC Toshiba inverter was used to change the initial wind velocity, which ranges from $5 \mathrm{~m} / \mathrm{sec}$ to $20 \mathrm{~m} / \mathrm{sec}$. Mesh wire screens were inserted at the tunnel exit to keep the flow uniform and smooth. The center of the turbine rotor was located at $1.5 \mathrm{~m}$ downstream from the wind tunnel exit, Hayashi, et. al.(2007).

A set of airfoil blades has a chord length of $80 \mathrm{~mm}$ was designed according to Joukowski profile (553) with a maximum thickness to chord length of $20 \%$.,
Yahya (1983). Two turbine rotors were designed and tested at various blade pitch angles. The first rotor has two blades, and in the second model four blades were used, Fig.(2). The dimensions of radius and height of the rotor are $150 \mathrm{~mm}$ and $200 \mathrm{~mm}$, respectively. The pitch angle was chosen as $15^{\circ}, 30^{\circ}$, $45^{\circ}$, and $60^{\circ}$. Flaps of the same Joukowski profile have a chord length of $20 \mathrm{~mm}$ were attached to the trailing edge of the rotor blades. The flap was located at approximately $3 \mathrm{~mm}$ down of the trailing edge and made $5^{\circ}$ from the blade axis in the clockwise direction, Fig.(3). The blades and flaps were manufactured on a milling machine with a fly cutter.

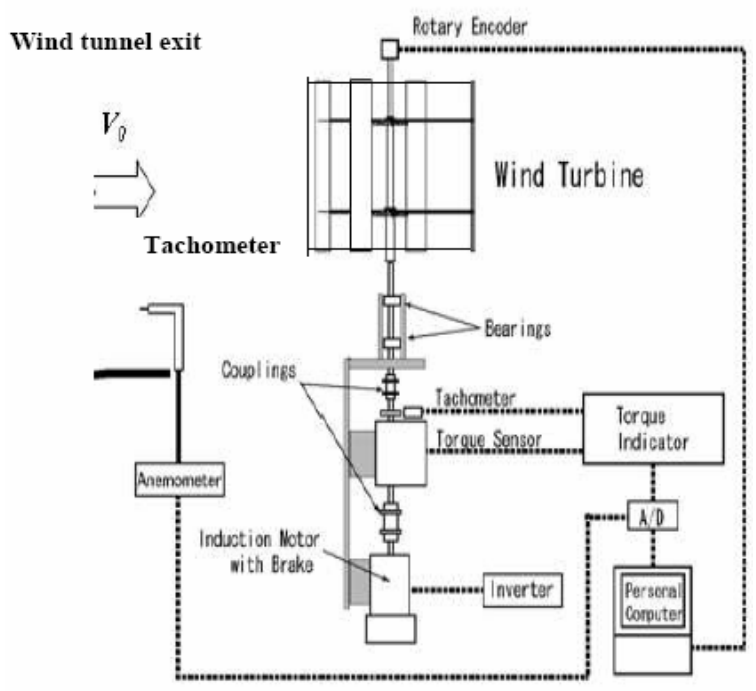

Fig.1 Schematic layout of experimental apparatus
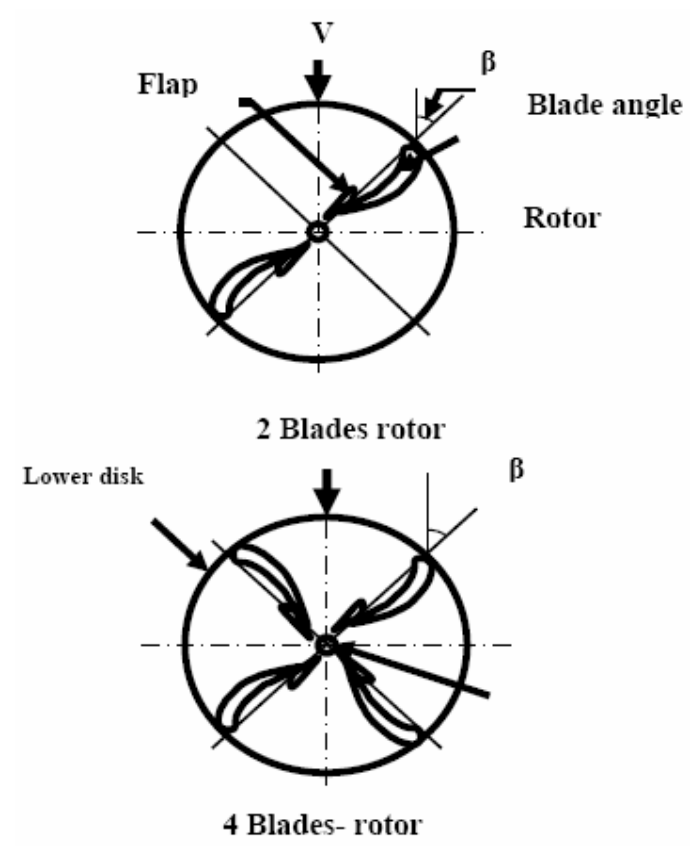

Fig.2 The turbine rotor models 
The central shaft is made of torsion free steel and has a diameter of $20 \mathrm{~mm}$ and length of $600 \mathrm{~mm}$. It is held at the bottom by two ball bearings mounted inside a cylindrical woodenblock $200 \mathrm{~mm}$ diameter and $150 \mathrm{~mm}$ height. The blades are supported with two horizontal circular disks, $350 \mathrm{~mm}$ diameter made of steel. The lower disk is fixed by welding with the rotating shaft. The upper disk is free and fixed with the top of blades by screws.

The rotor axis is combined through couplings with both the digital torque detector (ONO SOKKI, SS-002) and the induction motor which is controlled by an inverter. As the measurement conditions, wind speed was measured at the wind tunnel exit using a light tachometer. The obtained torque data were corrected by adding the braking torque measured when the axis from which all blades were removed was rotated at the same rotational speed.

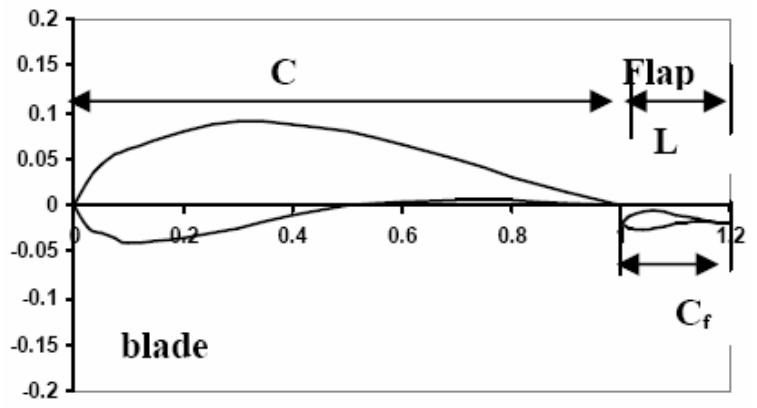

Fig.3 The rotor blade with flap

A set of experiment was carried out to establish the effect of the flap position on the turbine performance. Fig.(3) shows the rotor blade and the attached flap. All experiments were carried out at zero angle of attack.

\subsection{Uncertainty Estimates}

Estimates of the experimental uncertainty were performed. The results are as follows:

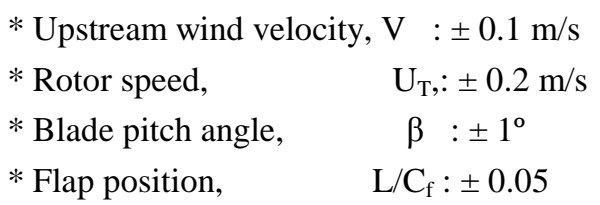

\subsection{Power and Torque Coefficients}

The power coefficient $C_{p}$ is a function of wind turbine rotor characteristics and tip speed ratio. It is given by the following formula, Katz and Plotkin, (1991).

$$
\begin{aligned}
& C_{T}=P_{R} /\left(0.5 \rho A V^{3}\right) \\
& C_{p}=T_{R} \omega /\left(0.5 \rho A V^{3}\right)=T_{R} \lambda /\left(0.5 \rho v^{2} r_{m}\right)
\end{aligned}
$$

where $P_{R}$ is the realizable power from the wind turbine, $T_{R}$ is the measured torque, and $\omega$ is the angular velocity of rotor. Also the torque coefficient $\mathrm{C}_{\mathrm{T}}$ is given by:

$$
C_{t}=T_{R} /\left(0.5 \rho A V^{2} r_{m}\right)
$$

\section{RESULTS AND DISCUSSION}

Experimental data are presented in the form of torque and power coefficients against the tip-speed ratio. Fig.(4) shows the torque coefficient versus the tip speed ratio for the two-blades turbine rotor model without flaps. It is observed that the rotor has a pitch angle $=45^{\circ}$ gives an optimum value of the torque coefficient as compared with other blade angles. In this case, the maximum torque coefficient is $34.1 \%$ which occurs at $\lambda=4$. While the pitch angle of $15^{\circ}$ gives a maximum torque coefficient $=27 \%$ at $\lambda=4.1$. For the case of pitch angle $=30^{\circ}$, the maximum torque coefficient is $27.8 \%$ which obtained at $\lambda=4.2$.

As the pitch angle increases to $60^{\circ}$ the maximum torque coefficient decreases to $31.7 \%$ which obtained at $\lambda=3.8$. Hence, one can say that the optimum value of the torque coefficient is a function of the blade pitch angle.

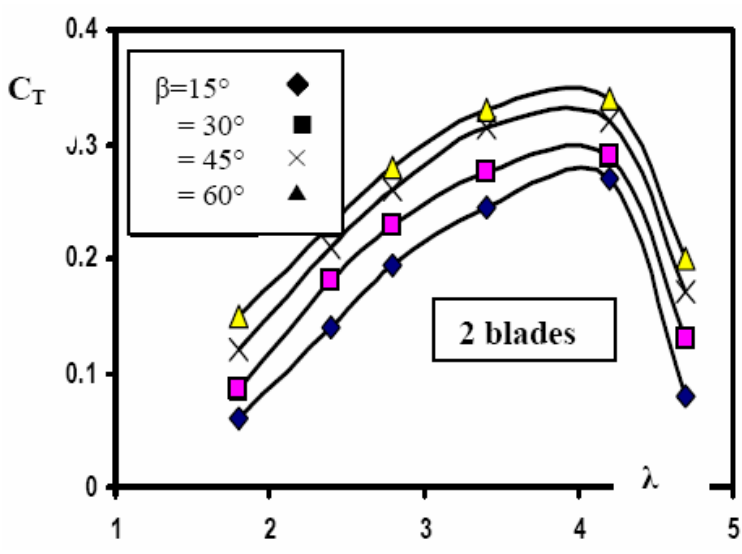

Fig.4 The torque coefficient Vs. tip speed ratio

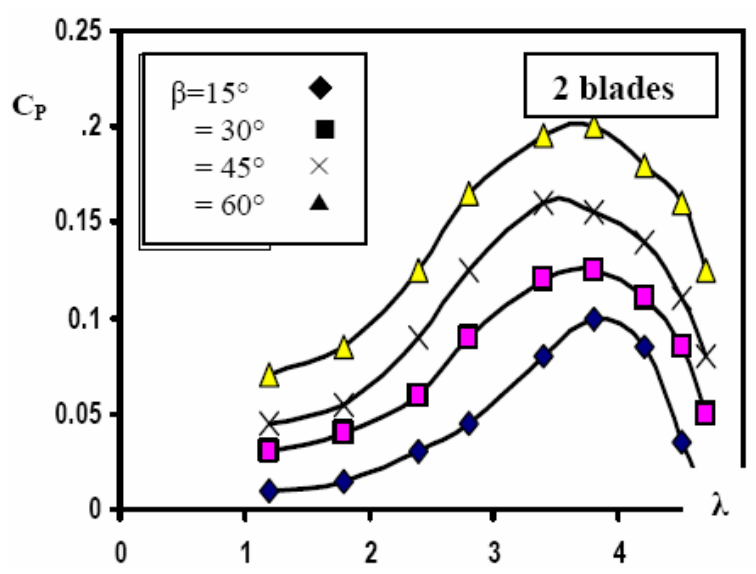

Fig.5 The power coefficient Vs. tip speed ratio 
Figure 5 shows the variation of the power coefficient with the tip-speed ratio for the two-blades wind turbine rotor without flaps. It is seen that the power coefficient increases with increasing the blade pitch angle up to $45^{\circ}$ and then decreases for higher values of $\beta$. For $\beta=15^{\circ}$, the maximum power coefficient is $10.3 \%$ which occurs at $\lambda=4.1$. For $\beta=$ $30^{\circ}$, the maximum power coefficient is $13.8 \%$ that occurs at $\lambda=4.2$. With increasing the pitch angle to $45^{\circ}$, the maximum power coefficient is $21 \%$ which occurs at $\lambda=4$. While for $\beta=60^{\circ}$, the maximum power coefficient is $17.5 \%$ that obtained at $\lambda=3.4$. Therefore, the blade angle of $45^{\circ}$ is the also the optimum angle which gives a higher power coefficient.

Figure 6 shows the variation of torque coefficient with the tip speed ratio for the four-blades rotor without flaps, tested at different blade angles. It is seen that, for $\beta=15^{\circ}$ the torque coefficient grows from still to a peak value of $28 \%$ which obtained at $\lambda=6.25$. The increase in the blade pitch angle from $15^{\circ}$ to $45^{\circ}$ leads to an increase in the torque coefficient. The pitch angle $45^{\circ}$ gives a maximum torque coefficient and equals $40 \%$, which occurs at $\lambda=6.47$. With increasing $\beta$ from $45^{\circ}$ to $60^{\circ}$, the maximum torque coefficient decreases to $=38 \%$, and obtained at $\lambda=6.37$.

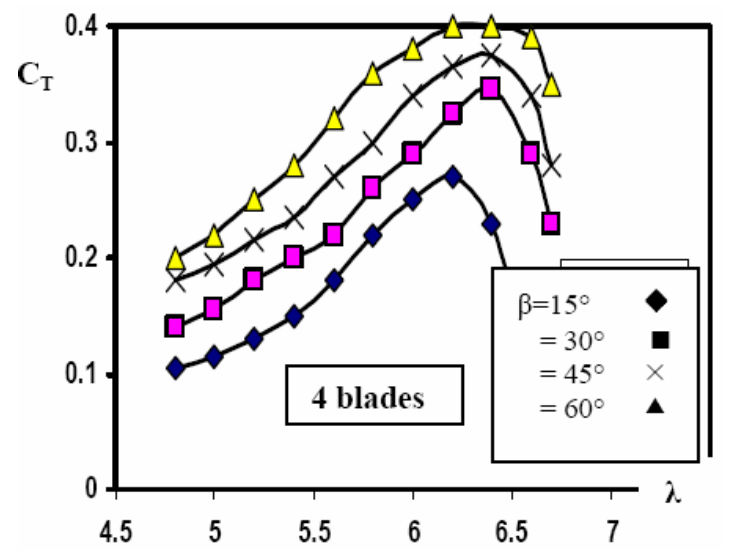

Fig.6 The torque coefficient Vs. tip speed $r$

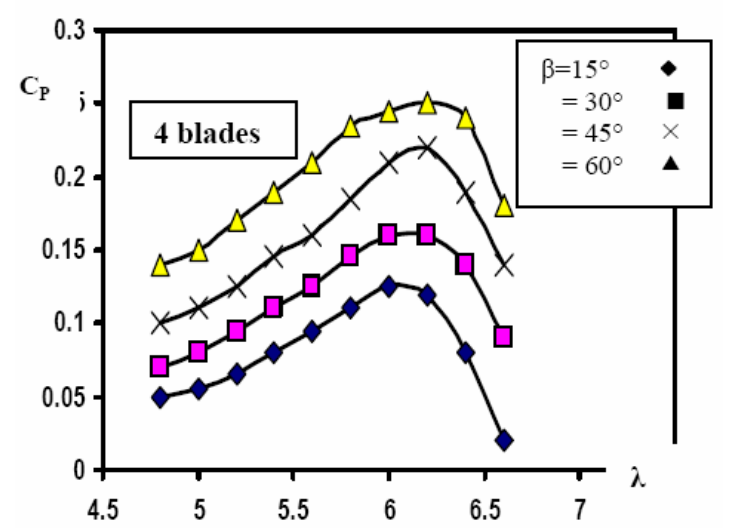

Fig.7 The power coefficient Vs. tip speed ratio
Figure 7 shows the relation between the power coefficient and the tip-speed ratio, for the four-blades wind turbine rotor without flaps. It is seen that the power coefficient increases with increasing the blade pitch angle from $15^{\circ}$ to $45^{\circ}$ and then decreases for the higher values of the pitch angle, $\beta=60^{\circ}$. The maximum power coefficient for $\beta=15^{\circ}$ is $12 \%$, obtained at $\lambda=6.25$. For $\beta=30^{\circ}$, the maximum value is $16 \%$, seen at $\lambda=6.31$. For $\beta=45^{\circ}$ the optimum power coefficient is $25.1 \%$ which occurs at $\lambda=6.4$. While the maximum power coefficient is $22.6 \%$ that occurs at $\lambda=6.27$ and $\beta=60^{\circ}$. Therefore, the blade pitch angle of $45^{\circ}$ is also the optimum angle which gives a higher power coefficient compared with other values of the pitch angle. Figure 8 represents the comparison between the power coefficient for the rotor has two and four blades at $\beta=45^{\circ}$. It is noticed that the generated power depends on the rotor design and rotor speed. The maximum power is evident with the rotor has four blades when rotates at a higher speed. For the case of two blades rotor, the maximum generated power is obtained at a lower tip speed ratio compared to the four blades rotor.

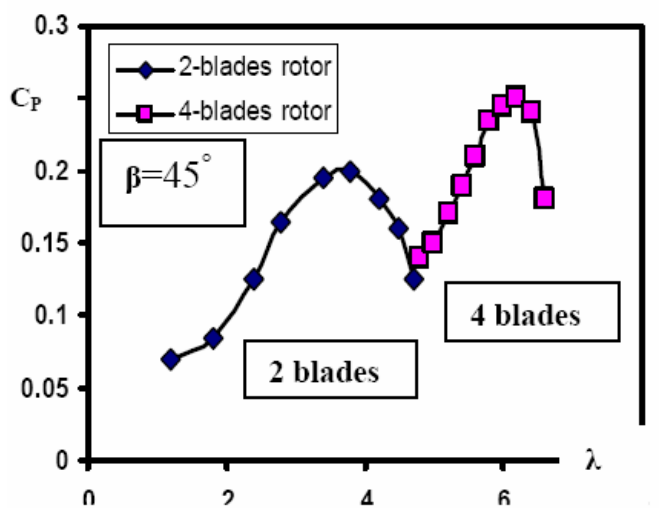

Fig. 8 A comparison between two and four blade rotors

The power coefficient versus the tip speed ratio is presented in Fig.(9) and Fig.(10) for turbine models with flaps and $\beta=45^{\circ}$. The results for the rotor without flaps are given for comparison. In Fig.(9), it is noticed that the attached flaps at the blade trailing edge leads to an evident increase in the power coefficient compared to the model without flaps. The peak value of $\mathrm{C}_{\mathrm{p}}$ is $21.4 \%$ for the flap set at $\mathrm{L} / \mathrm{C}_{\mathrm{f}}=1$. It increases to $=22.5 \%$ for $\mathrm{L} / \mathrm{C}_{\mathrm{f}}=0.75$, and then decreases to $=20.7 \%$ for $\mathrm{L} / \mathrm{C}_{\mathrm{f}}=0.5$. It decreases again to $=20.5 \%$ for $\mathrm{L} / \mathrm{C}_{\mathrm{f}}=0.25$. This means that the ratio $L / C_{f}=0.75$ is the optimum value that gives a higher power with an improvement, $\left(\mathrm{C}_{\text {pwith }}\right.$ $\mathrm{C}_{\text {pwithout }} / \mathrm{C}_{\text {pwithout }}$ ) equals $7.14 \%$, when compared with that of the model without flaps. This means that the attached flap reduces the flow separation, increases the lift, increases the captured energy from the incoming wind and then increases the generated power. 


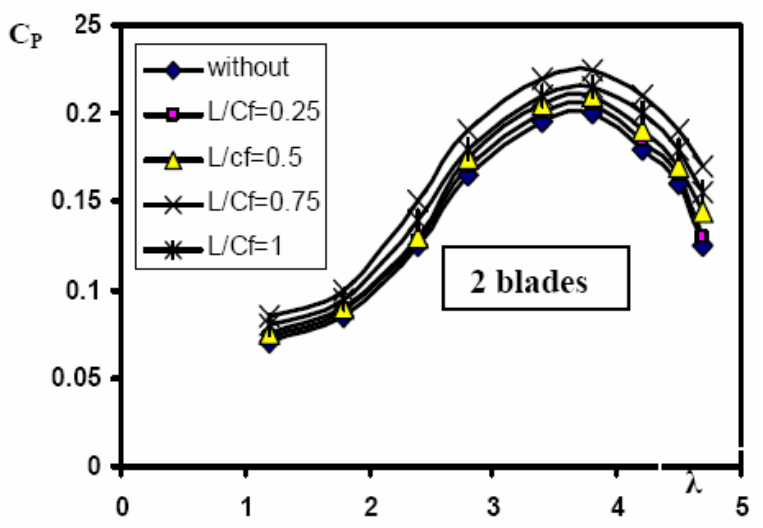

Fig.9 The power coefficient Vs. tip speed ratio for two blades rotor with flaps

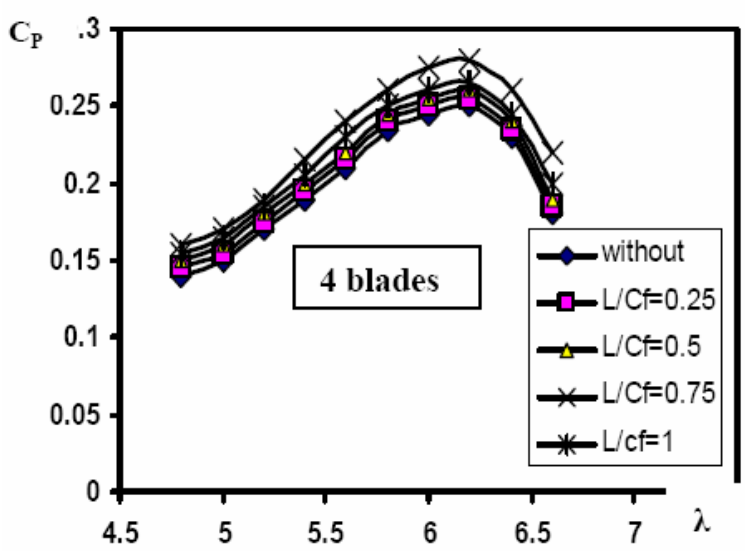

Fig.10 The power coefficient Vs. tip speed ratio for four blades rotor with flaps

Figure 10 shows the same results for the rotor has four blades and $\beta=45^{\circ}$. The maximum power coefficient for the rotor without flaps is $25.1 \%$ which occurs at $\lambda=6.4$. For the rotor with flaps, fixed at $\mathrm{L} / \mathrm{C}_{\mathrm{f}}=1$, the maximum power coefficient increases to $26.5 \%$ with an improvement of $5.58 \%$. As changing the flap position, $\mathrm{L} / \mathrm{C}_{\mathrm{f}}=0.75$, the maximum power coefficient increases to $28.3 \%$ which gives an improvement of $12.7 \%$. For $\mathrm{L} / \mathrm{C}_{\mathrm{f}}=0.5$, the maximum power coefficient is $26 \%$ and the improvement in the power coefficient is $3.58 \%$. When the flap moves to $L / C_{f}=0.25$, the maximum power coefficient is 25.5, with an improvement $=1.59 \%$. Hence, it is also noticed that, using flaps at the trailing edge gives an increase in the power coefficient and the maximum improvement is 12.7 $\%$, occurs at $\mathrm{L} / \mathrm{C}_{\mathrm{f}}=0.75$ and $\beta=45^{\circ}$.

Figure 11 shows a comparison between the two and four-blade rotors with and without flaps at $\beta=$ $45^{\circ}$ and $\mathrm{L} / \mathrm{C}_{\mathrm{f}}=0.75$. The attached flap increases the turbine power. This is because the attached flaps reduce the flow separation, increases the lift, capture more wind energy, increase the rotor speed and hence increase the turbine power. The maximum power occurs at different values of the tip speed ratio depends on the rotor design. Therefore, one can say that the captured power is a function of the tip speed ratio and rotor design.

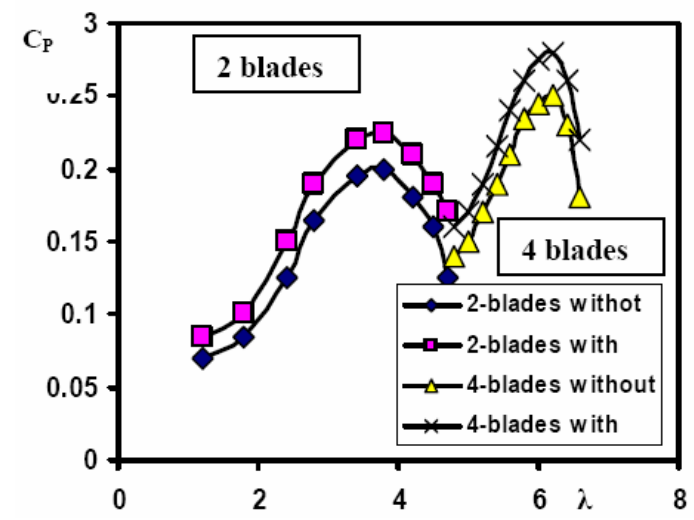

Fig.11 A comparison between two and four blade rotors with two and four blade rotor

\section{CONCLUSION}

A small-scale model vertical axis wind turbine was designed to study the effect of an addition flap surface to the trailing edge of the blade on the turbine performance. The position of the flap was changed to give a higher power coefficient. Turbine rotors have two and four blades were tested at different tip speed ratios. Experiments were done at a wide range of blade pitch angles from $15^{\circ}$ to $60^{\circ}$. Using trailing edge flaps at an optimum position reduce the flow separation, enhance lift, capture more wind energy, increase the rotor speed and hence increase the turbine power. The power and torque coefficients increase with an increase of the blade pitch angle up to a value of $45^{\circ}$ and then decrease with the higher value the pitch angle. The optimum position of the attached flap is found at at $L / C_{f}=0.75$. The improvement in the power coefficient is a function of the tip speed ratio which depends on the rotor design. The rotor has two blades gives an improvement equals $7.14 \%$ while this value increases to $12.7 \%$ when using the rotor has four blades, compared with the rotor without flaps.

\section{Nomenclature}
A : Area swept by turbine
C : Blade chord
$\mathrm{C}_{\mathrm{f}}$ : Flap chord
$\mathrm{C}_{\mathrm{p}}$ : Power coefficient
$\mathrm{C}_{\mathrm{T}}$ : Torque coefficient
D : Rotor tip diameter

$\mathrm{L}$ : Distance of flap free from blade surface

$P_{R}$ : Measured power $=T_{R} \times \omega$

$\mathrm{T}_{\mathrm{R}}$ : Measured torque.

$\mathrm{r}_{\mathrm{m}}$ : Rotor mean radius

$\mathrm{U}_{\mathrm{T}}$ : Turbine speed 
$\mathrm{V}$ : Upstream wind velocity

$\beta$ : Blade pitch angle (angle between blade chord and axis of rotation)

$\rho \quad$ : Air density

$\lambda \quad$ : Tip speed ratio $\left(\mathrm{U}_{\mathrm{T}} / \mathrm{V}\right)$

$\omega$ : Angular velocity

\section{REFERENCES}

[1] Abd Elmotalip,A.,2005,"Influence of Extended Curved Vane on a Vertical Axis Wind Turbine Performance." Port Said Engineering Research Journal,Vol.9, No.2, pp. 81-92.

[2] Allet,A., and Paraschivoiu, I., 1995, "Viscous Flow and Dynamic Stall Effects on Vertical Axis Wind Turbine", Int. J. of Rotating Machinery,Vol.2, No. 1, pp. 1-14.

[3] Alinot,C., and Masson, C., 2002, "Aerodynamic Simulations of Wind Turbines Operating in Atmospheric Boundary Layer With Various Thermal Stratifications", AIAA-0042.

[4] Butterfield, C. P., Scott, G., and Musial, W., 1992, "Comparison of Wind Tunnel Airfoil Performance Data with Wind Turbine Blade Data," Journal of Solar Energy Engineering, Vol. 114, May, pp 119-124.

[5] Duque, E., Johnson, W., VanDam, C.P., Cortes, R., and Yee, K., 2000, "Numerical Predictions of Wind Turbine Power and Aerodynamic Loads for the NREL Phase II Combined Experiment Rotor",AIAA,No. 0038.

[6] Fujisawa, N., and Gotoh, F., 1994, "Experimental Study on the Aerodynamic
Performance of a Savonius Rotor," Transactions of the ASME, Vol. 116, August, pp 148-152.

[7] Gaunaa, M., and Johansen,J., 2007, "Determination of the Maximum Aerodynamics Efficiency of Wind Turbine Rotors with Winglets," The Science of Making Torque from Wind, Journal of Physics Conference Series 75.

[8] Gavanidou, E. S., Bakirtzis, A. G., and Dokopoulos, P. S., 1992, “ A Probabilistic Method for the Evaluation of the Performance of Wind-Diesel Energy Systems," IEEE Transaction on Energy Conversion, Vol. 7, No. 3, September, pp 418-425.

[9] Hayashi, T., Hara, Y., Azui, T., Kang, S., (2007), "Transient Response of a Vertical Axis Wind Turbine to Abrupt Change of Wind speed",e-mail: hayashi@ecowind.jp

[10] Iqbal, M.T., 2003, "Modeling and Control of a Wind Fuel Cell Hybrid Energy System", Renewable Energy, Vol. 28, pp. 223-237.

[11]Katz, J. and Plotkin, A., 1991, "Low Speed Aerodynamics", From Wing Theory to Panel Methods, McGraw-Hill, Inc.

[12] Katz, J. and Plotkin, A., 2006, "Low Speed Aerodynamics", Cambridge University, Press.

[13] Takao, M., Maeda, T., Kamada, Y., Okj, M., and Kuma, H., 2008, " Straight-bladed Vertical Axis Wind Turbine with a Directed Guide Vane Row," Journal of Fluid Science Technology, Vol. 3, No. 3.

[14] Yahya, S. M., 1983, "Fluid Dynamics," Wiley Eastern Lim., New Delhi, India. 